\title{
Engaging novice teachers in semiotic inquiry: considering the environmental messages of school learning settings
}

\author{
Bonnie Shapiro
}

Received: 19 December 2013/ Accepted: 19 December 2013/Published online: 4 February 2014

(C) The Author(s) 2014. This article is published with open access at Springerlink.com

\begin{abstract}
Katherine Fogelberg's insightful study of the messages of zoo signs describes the complex, sometimes contradictory nature of the messages they communicate. The construction and content of signs are influenced by institutional power. Fogelberg argues that the creation of zoo signage designed to inform the public can, through its messages, silence a perspective of care and compassion for animals. The research presented in the following article extends discussion about the value of critical considerations of cultural and institutional messages created and read in another type of setting designed to educate and inform, the school learning setting. The article reports on a project that engaged novice teachers in explorations of the nature and types of environmental messages found in learning settings. During our inquiry work together, novice teachers suggested areas of particular concern to them, and began to construct ideas about aspects of their work in which they plan to take action or engage in future inquiry. The research also reveals some of the challenges involved when novice educators first begin the process of engaging in semiotic interpretive readings of learning settings.
\end{abstract}

Keywords Semiotic interpretive studies - Environmental education · Novice teacher engagement

Many science and environmental educators suggest that deeper knowledge of the ways we communicate with one another about the natural world is essential to build the commitment and understanding needed to solve environmental problems, as suggested by Julia Corbett (2006). Mitchell Thomashow (2002) suggests that this commitment is best developed through personal

Lead Editor: L. Bencze.

This review essay addresses issues raised in the K. Fogelberg paper, Unsilencing voices: A study of zoo signs and their language of authority.

B. Shapiro $(\bowtie)$

Werklund School of Education, University of Calgary, Calgary, Alberta, Canada

e-mail: bshapiro@ucalgary.ca 
engagement and experiences, such as autobiographical work to create understanding of one's own ecological identity. In my university classes, teachers in preparation are encouraged to build awareness of critical distinctions through engagement in semiotic interpretive conversations as they examine both scientific (Shapiro \& Kirby 1998) and environmental messages and values of learning settings (Shapiro 2012). The research reported here is based on a project designed to help novice teachers understand some of the ways that the messages of school institutions communicate and educate students about the human/nature relationship, and to learn how they understand these messages. Novice teachers were engaged in semiotic readings of learning environments in naturalistic settings and identified interpretive themes that emerged for them in this work. The research also documents some of the challenges participants experienced while engaging in semiotic interpretive work.

As a science educator, I help students build understanding of the ways that messages are created in learning settings. They are created not only by the teacher, but also through the ways that institutions represent cultural values in the organization and design of schools. As a member of the cultural community, the teacher is influenced by these values in their teaching work. I asked a group of former students, newly graduated, to expand and extend some of the ideas we worked with in my classes. I let them know that I wanted to build insight into what deeper considerations of these ideas meant for them. Together, through readings, school visits, group dialogue and interviews, 10 novice teachers used semiotic interpretive perspectives to articulate ideas about the environmental messages of learning environments. A major goal of this work is to help new teachers become open to the possibility that the messages of learning environments are deeply rooted in cultural values and that these messages may sometimes teach more powerfully than text and lecture. Another purpose of this work is to help teachers become wide-awake to possibilities as they consider their roles in the creation of messages. Viewed as forms of text, physical and cultural features of the school learning setting can be used to reinforce and reproduce positive perspectives of care and concern for the environment. I involve students in readings of John Fien's work (1993) to help develop ideological distinctions between educational approaches that build knowledge and awareness for the environment as opposed to experiences that teach about or through the environment. Learning settings are created not only for the purpose of reproducing cultural values and norms, but are themselves examples of the values and patterns of cultural constructs of the larger group that created them, and so it is very appropriate that novice educators consider the messages of these settings. As novice teachers examine the messages of learning, they also begin to see how knowledge of their own cultural values, and the values of the dominant culture may not always teach or model positive knowledge and behaviors relating to environmental concerns. We discuss how, with this knowledge, educators may help disrupt less useful messages about sustainable practices and positive ecological interactions. Throughout our conversations, novice teachers suggested areas of particular concern to them, and made note of areas where they would like to take future action or inquiry. The research also revealed challenges and dilemmas encountered when engaging in semiotic interpretive readings as a form of professional inquiry.

\section{Research framework and approach to involving novice teachers}

I have used interpretive studies in science and environmental education as resources for considering the values, meanings, and practices embodied in the physical, social, and culturally constructed structures of educational systems (Shapiro 2010). Interpretive approaches 
such as semiotics offer a valuable means to engage novice teachers in the examination and critique of learning settings. Using photographs and artifacts, such as texts and transcripts of teaching and learning events, I share examples of semiotic readings based on some of the learning settings I have explored. These discussions serve as a springboard for considering learning in new ways. I find this work of great interest to educators because school settings are particularly fruitful environments for developing, through thoughtful readings of the activities there, positive appreciative approaches to examining learning as recommended by Frank Barrett and Ronald Fry (2005). In addition, our work embraces thoughtful critical appraisals of practice in ways that address the values, meanings, and practices of environmental education as suggested by Joanne Bauer (2006).

The research framework used to investigate messages about learning environments is rooted in semiotic interpretive studies. Semiotics involves the study of signs and symbols as important aspects of human communicative behavior. Sharing the evolving nature of semiotic interpretive work provides an informative foundation for novice teachers. Semiotics has a long tradition in the social sciences and is a synthesis of a number of approaches that study social meaning and action. It began in Europe as semiology, described by Swiss linguist, Ferdinand de Sassure (1959), who viewed language as a system of signs. He asserted that words do not have meaning in isolation but obtain their meanings due to their placement in a larger system of signs and sign systems. His foundational work led to Charles Peirce's (1985) theory of communication and signification. Modern anthropology and the ecological approach to the study of mind developed by Gregory Bateson (1972) also serve as foundational resources for studies in social semiotics. Social semiotics goes beyond formal semiotics to study how human beings use signs to construct the life of a community. Social semioticians examine how signs and sign systems are used as codes to communicate in a particular society or culture. One of the major purposes of social semiotics has been to unite the study of human behavior with the study of society, making it a particularly appropriate basis for the study of educational systems of communication. Thomas Sebeok (2001) notes how semiotics is "both a science with its own corpus of findings and theories and a technique for studying anything that produces signs, and it is a particularly good fit for the study of educational systems" (p. 5).

I share my own semiotic interpretive work with practicing teachers and student teachers in science and environmental education to help them think about the potential of understanding the ways that signs and symbols in learning settings engage learners in the environments they create for their students, but also, as part of the environment that is created for those who dwell in the learning setting, including teachers. In my classes and professional development seminars, we start by viewing photographs of learning settings to consider the ways students, and all who inhabit learning settings, read the messages as forms of everyday cultural text. I then invite student teachers to go into assigned settings in small groups to a wide range of areas on campus to consider some of the environmental structures and messages that exist on campus. We discuss their findings and interpretations and the values that are behind them as semiotic signs, sign systems, and systems of signification. These experiences lead to thoughtful discussions that consider how powerful cultural messages presented through these structures might be more explicitly designed to inform learner understandings, ideally to create positive messages of care for human beings, ecological values, and relationships with the natural environment and in learning settings. These dialogues have been lively and engaging and have helped deepen understanding of the meaning of the signs and symbols that are read as text in learning settings.

Previous research work in science education identified some of the sources of the messages and values of science that are represented in our culture and the ways cultural 
values and beliefs about science knowledge are embodied in the artifactual world of the school setting. Bonnie Shapiro and David Kirby's (1998) research based taxonomy on the kinds of messages conveyed about science learning is shared with student teachers in my classes. The taxonomy is presented in Table 1 .

Reference to the taxonomy has allowed us to direct our conversations and discussions to considerations of aspects of everyday cultural knowledge that might be used more explicitly as a form of text to build learner understandings and values. To achieve this, a second taxonomy was developed to describe environmental messages in learning settings (Shapiro 2012).

\section{Extending the research to environmental education learning settings}

I have found value in extending the research on messages about science to a project studying the kinds of environmental messages that might be read and understood in learning settings. This work involved an exploration of educators' perspectives on the nature of these messages, leading to the creation of a second taxonomy of ideas about the environmental messages of learning settings (Shapiro 2012). This taxonomy is presented in Table 2. The project also explored the development of ideas about the kinds of environmental values (Shapiro 2012, p. 12) that underlie these messages. The Environmental Messages taxonomy was shared with novice teachers in the present research which extends this work as an effort to understand the nature and content of novice teacher engagement in semiotic interpretive studies of the environmental messages of learning environments. Several subquestions guided the research:

- What are some of the main areas raised in the discussion?

- What are some of the key insights and points raised in conversation?

- What are some of the benefits of engaging novice teachers in semiotic interpretive conversations about the environmental messages of learning environments?

- What are some of the challenges of engaging in this work as novice teachers are invited to examine learning settings using a semiotic interpretive perspective?

The research process is described below followed by a presentation of some key themes that emerged while examining the data using the research questions as a guide for the coding and theme development process.

The research process After completing a course with me, and graduating from their Bachelor of Education program, 10 novice teachers volunteered to participate in the project. All of our meetings and conversations occurred outside the university setting. Each participant had successfully completed a final teaching practicum experience and all were after-degree students, meaning that each had acquired teaching certification after having completed a range of previous university degrees. Two held degrees in fine arts (drama, painting), three in science (forestry, biology, physics), two in physical education, one in engineering, one in architecture, and one in anthropology, specializing in archaeology. Four of the participants were born in, or had lived in, a cultural community outside of Canada or the United States for five or more years prior to living in Canada. Six of the novice teachers were female, four were male. Following a review of the meaning and nature of semiotic interpretive work, and a review of the Environmental Messages Taxonomy (Table 2), we visited two schools together. We used the school visits to stimulate thinking about semiotic interpretive messages in schools. During the school visits, participants engaged with the researcher in individual interviews and group discussions to 
Table 1 Types of semiotic messages in the school science learning environment

Architectural messages

Reading the school building

The school yard environment

Entry to the school

Structure of the building/organization of rooms within the setting

Special places for science within the structure

Classroom messages

Messages of science on walls, bulletin boards, and other spaces

Furniture arrangements/seating

Arrangements for science learning about the environment-science corner, tables, work space, special facilities, sinks

Text and curriculum messages

Resources used for teaching and learning science

Images of science/images of scientific procedures/images of scientists

Portrayals of science as content/activities of scientists

Science/technology connections

Social/behavioral messages

Activity structures/rituals of social interaction

Rules of conduct/rituals of interaction and behavior

Teacher placement viz- $a$-viz student places

Invitation of parents and other speakers into the classroom

Teaching approaches

Teaching strategies

Teacher enthusiasm for the topic

Science fairs/home projects

Relative priority of science viz- $a$-viz other curriculum topics

Testing practices

Policy messages

School administration

Timetabling

Nature of science leadership within the school

Library

Emphasis on acquisition of environmental resources

Library displays

Extra to classroom experiences-science clubs, science fairs, field studies, tree planting days, schoolwide environmental or science programs, special speakers

Financial resources allotted to environmental education

Generalist or specialist teaching emphasis

Collaboration among teachers

Physical Use of School Facilities

Special storage room

Special science classroom

District

Support for science consultancy role

District resource center for educators 
Table 1 continued

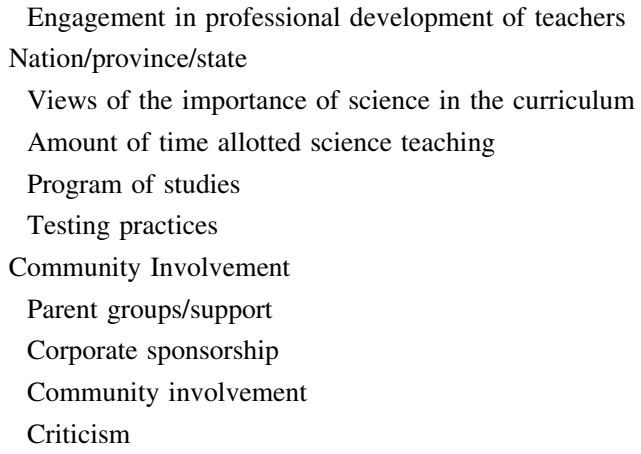

From: Shapiro \& Kirby (1998, pp. 230-231)

articulate their observations. Conversations were designed to help participants make connections to memories of their own initial experiences in schools in the previous year as student teachers. Five participants joined the researcher in an elementary school setting and five joined the researcher in a high school setting. Activities in the school included observing and participating in classroom experiences, touring the school building and grounds, viewing photographs in small group discussion, and speaking with students, teachers, staff, administrators, and parents in the two school settings.

Interviews and group dialogue with the participants began with a consideration of features of the taxonomy developed in the Science Messages project work (Shapiro \& Kirby 1998). This work was extended through ongoing school visits and discussion with teachers, administrators and students to develop a second taxonomy to consider the types of Environmental Messages of Learning Environments (Shapiro 2012).

As an initial guiding structure, I encouraged participants to consider the primary categories of the framework of the taxonomy as a lens for observations.

1. Architectural messages.

2. Text and curriculum messages.

3. Social/behavioral messages.

4. Policy messages.

\section{Collecting information on participants' perspectives about the environmental messages of learning settings}

As described above, activities in the school included observing and participating in classroom experiences, touring the school building and grounds, viewing photographs in small group discussion, and speaking with students, teachers, staff, administrators, and parents in the two school settings. Group interviews took place immediately after each school visit. Conversations and interviews were recorded and transcribed. Observational data was collected in the form of photographs and written notes describing the settings and activities in the settings that were observed by all participants. Handwritten notes also documented observational information that described informal interactions with teachers and administrators. Some individual interviews also took place at the university over the two- month period following the school visits. 
Table 2 Considering the types of environmental messages in learning settings

\author{
Architectural messages \\ Reading the school building \\ The physical setting of the building/placement in the community \\ Entrances to the building(s) \\ Architectural features-artistic/purposeful \\ Structure of the building/organization of rooms and furniture within the setting \\ Existence of designated spaces for environmental learning \\ Signage around the school that speaks to caring for and preserving the natural setting \\ Classroom Messages
}

Messages of interest in, concern and action for the environment on classroom walls, bulletin boards, other spaces

Furniture arrangements, seating

Arrangements for learning about the environment-natural materials, tables, displays, facilities

Images of learners on classroom walls engage in studies of the environment

Text and curriculum messages

Resources for teaching about environmental education

Images of the environment/methods available for study/images of those who study the environment professionally

Portrayals of environment as subject matter content/activities of environmental researchers

Science/environment/technology connections

Social/behavioral messages

Activity Structures/Rituals of Social Interaction

Rules of conduct/rituals of interaction and behavior

Use of social media tools and technologies to build awareness of and promote stewardship of then environment

Invitations to those outside the community, parents, speakers and others

Organization of environment/furniture, etc.

Existence of clubs to help learners support environmental learning

Teaching Approaches

Teaching strategies that guide learning behaviors

Lecture, Problem solving, Action learning, Activism

Teacher enthusiasm for the topic

Environmental fairs/home projects

Relative priority given to environmental education

Opportunities for student inquiry/research

Involvement of parents

Opportunities for out of classroom activities

Policy messages

School Administration

Timetabling — amount of time devoted to environmental/sustainability topics

Nature of environmental leadership in the school

Library resources available

Emphasis on acquisition of environmental resources

Library displays 
Table 2 continued

Extra to classroom experiences_environmental clubs, activities, field studies, tree planting days, school-wide environmental or science programs, special speakers

Financial resources allotted to environmental education

Generalist or specialist teaching emphasis

Collaboration among teachers

Physical Use of School Facilities

Special environmental resources distribution area

Special rooms or outdoor spaces set aside for environmental education

District

Support for environmental consultancy role

District resource center for educators

Nation/province/state

Views of the importance of environmental education in the curriculum

Amount of time officially allotted to environmental education

Existence of a program of studies devoted to environmental learning

Testing practices/standards of achievement

Community Involvement

Community involvement/Parent groups/support

Corporate sponsorship

Media involvement

Opportunities for meeting with community, city, regional, provincial and national government representatives; valuing of open dialogue and criticism

Encouragement of volunteerism and activism in the community

\section{Organizing and representing the research findings}

The research data were carefully reviewed with the key research questions placed alongside the transcripts throughout the data analysis activity. Using the research questions as an organizing framework, the coded interviews were further transformed to build a summary of themes representing some of the observations, thoughts, concerns, and topics relating to considerations of the environmental messages the novice teachers identified as worthy of further inquiry. As they shared these possibilities through critique and challenging conversations, students opened to some important possibilities that emerged for them personally as future creators of messages for teaching and learning. These were sometimes presented as dilemmas that participants wished to unravel. I present several of these dilemmas and provide transcript segments to illustrate the ways participants identified areas that they wished to pursue further as professionals.

A very large amount of interview and observational data was collected and analyzed. Key findings are represented using transcript data to illustrate significant themes. Two major theme areas were identified based on the research subquestions. The first Theme Area addresses the first three subquestions. The second Theme Area addresses the last subquestion.

Theme Area I: The construal of dilemmas and challenges for further inquiry in teaching practice by the novice teachers.

Theme Area I is illustrated by data that addresses the first three subquestions: 
- What are some of the main areas raised in the discussions?

- What are some of the key insights and points raised in conversation?

- What are some of the benefits of engaging novice teachers in semiotic interpretive conversations about the environmental messages of learning environments?

This theme is represented by emerging ideas and views that demonstrate novice teachers' interests in addressing issues in their future work or dilemmas they wish to take action on or consider further.

1. Sustainability practices. Messages about the organization and use of physical and expendable materials in the school. Several of the research participants looked for sustainability practices within the school, and spoke with administrators and teachers to learn about the ways they use materials and present an ethic of care through their actions.

Linnea: I see things around here that show some concern for the environment, really, like the way the teams of kids that were lugging the recycling bins and taking them downstairs to empty. They don't look terribly happy doing it (laughs) but I like that they are the ones doing it. Not the custodian. The kids will remember for a long time that they recycled in this school. I wonder if they are doing this as volunteers or whether it is a punishment or something connected with demerits. I want to make something like, happen and this should really be fun. I guess they don't have to have smiles on their faces though, to show that they value it.

Shapiro: That is something we can ask the teachers when they come down.

We asked the teachers about the students and their work to take the recycling to the larger bins and learned that the students engaged in this work are part of the school's Ecoclub. In many cases, we found that students in the school were the initiators of sustainable practices and, it was the students who urged recycling and reusing practices.

2. Messages about concern for environmental considerations in the construction and design of the school building and schoolyard site. Participants commented on their awareness of the ways that the physical building communicates messages to students about how the learning environment was valued and, the kinds of values that were guided school organization when the school was initially constructed.

Participant comments about the physical structure and uses of the physical school building school constituted the largest number of comments in the conversations. Several participants referred to the age of school buildings and noted features of the school in need of repair.

Thomas: Thinking about it this way, the school looks like it was... oh sort of built around the late $80^{\prime} \mathrm{s}$ or so. I really think that things may have changed a lot, you know...um, about how we learn and maybe in a school building like this, we should be changing things about the building... or the way we use it, to connect more to how we want students to learn. I really never looked at a school building like this, as something giving message about the environment or any other learning really, but it's true, you know.

Shapiro: What might you do to disrupt that? Or is it important to? Does the building speak to or give messages about the environment in this way?

Thomas: As far as the environmental messages of the school, I guess the first thing I'd do with students is look at, ... is the materials that the school is made of and at what cost to the environment-so what were the ideas like in the $80^{\prime}$ s about the thinking about materials and cost to the environment. Like, I don't know what the best kinds of materials are to use, 
frankly, to um, preserve the environment. And as for the hallway, well, um, we could put some tables out there, I guess, or have some places where kids can talk together about projects and such... you can do that in the classroom too. One thing I notice is that the libraries are not really used so much any more.

Lori: (Interrupts) Except for computer research. They do that.

Thomas: Or, really, I don't have anything to compare it to. But they could be used more for working on projects.

Shirley: You are really are impacted by the building design. You have to maneuver in it. It sort of organizes the way you can organize what you do as a teacher... the um, experiences to help students learn, and that could have an impact on what you teach, what they learn, in the long run I think. Like, if we want students to collaborate. We send them to the hallway in small groups sometimes, but really, what is there for them there? Just a hallway. I'd like to see a space marked out that tells them-we value your working together, talk together, make noise, a mess even ... and here is a space where you can do that-I'd like to make a big deal out of using all of the school, even outside the school grounds for learning.

Many novice teacher participants commented on how learning philosophy has changed, for example, towards inquiry learning and teaching and that practices based on these ideas may be constrained by physical structures put in place 30 or 40 years ago.

3. Messages of concern about a scarcity of the number and quality of environmental topics appearing in the curriculum. Participants examined curriculum documents and were invited into classrooms. Many, who were fairly recent graduates, expressed concern about the ways that environmental topics are integrated in the curriculum.

Vala: When we were in the classroom where the teacher was doing "Trees and forests," she (the teacher) said that some of the kids in her class had never been in a forest. I just could not imagine that, but it is true I guess. Kids from big city places or where there is just concrete and... or they were from poorer areas. She said that she was going to find a small forest in town to take them to and then, maybe a trip to a bigger one, just to get some exposure, sort of a background of experiences. I think that it is really important to know the backgrounds of your students that way, and before you start teaching the abstract ideas.

Shirley: I just don't see a lot of attention paid to environmental topics in the school curriculum and I am hoping that will change with the big revisions to curriculum that are coming. I really am hoping, and maybe there will be something that I can do to make or build more positive messages by having positive experiences.

Jose: Well, I saw the teacher who was working with popular culture in the social studies class having a debate with kids about the pipeline! And they had to do a lot of research beforehand and take different sides and such. So, if it is not in the curriculum, the teacher can still make a place for it. I think that kind of teacher is the one I want to be. As far as a message for kids, kids remember a teacher like that. They think of them as... someone who gave them something extra.

4. Several participants expressed concern about the lack of curriculum messages that address social impacts of environmental problems and issues in the school and in the larger community.

Kamal: In our visit to the social studies class, the instructor really tried to connect... it was a great model for something that I want to do... she went beyond sort of, in the study 
of ancient Greece to the ways that people used the physical environment, like the way they diverted water. I found that she tried to make connections to the ways we use the environment today. That was really great. It shows that the teacher is going beyond the standard, set objectives, so to speak... um and, so, she showed the class that there is more to history really, that it can be a message about today and, sort of the environments of today. I really like that approach.

Linnea: We have a lot of homeless people right now. What does the school really say about that? What kids can do. They can do a lot. I think there is a lot of good coming out of the service kinds of things that are going on in some of the private schools. Integrating kids into the community more. I didn't see that here. I talked with the teacher about it and she thought it might be a good way to go.

5. Participants discussed the nature and quality of opportunities for students to engage in direct experiences in natural settings and how the amount and quality of these experiences speak to learners about the value of first hand experiences in the environment as a vital part of academic work.

Marc: I want to ask them about the retreat program that Sam mentioned. They go out with the kids to a retreat at this school. That is sort of rare in this school, I mean rare for any school, really. So what message is there in that. Most schools don't do it. I want to organize in the school I teach into get students outside or out to other settings. I wonder how they connect that with what they are doing in the classroom or if it is something completely separate, you know, the environment is out there, and we are here.

6. Participants noted that encouraging the integration of collaboration as a form of learning speaks a message to learners about the value of learning to work with others as they engage in practical and academic work to address a task.

Jas: It is kind of hard at a high school to use the school grounds to study the environment in a big city like this, but they do that in elementary schools a lot. So, and we can ask them about the curriculum too. Like, how do the teachers make connections for the kids between the subjects. How well does the administration help teachers make collaborations among themselves? I am not familiar so much with the high school curriculum, but we did that a lot in the elementary program. Is it in the curriculum, or do the teachers do that themselves?

Ricardo: We saw this—-very young kids actually editing each others' work! It was about their stories on their field visit to the nature sanctuary. I really would like to learn from a teacher that helps them start working this way from the very start of the year. They were working in groups and had fabulous topics that they selected and they just seemed to know what they were doing all the time, what they were supposed to be doing the whole time. It was really phenomenal.

\section{Theme Area II: Participants experienced difficulty describing their understandings of the "nature of culture," and sought to deepen understanding of semiotics.}

Theme Area II is illustrated by data that addresses the last subquestion:

- What are some of the challenges of engaging in this work as novice teachers are invited to examine learning settings using a semiotic interpretive perspective?

Throughout our research conversations and structured interviews, several interesting aspects of engagement in the research project emerged that participants noted as challenging aspects of the work. Three of these challenges are identified and illustrated below: 
1. Some participants expressed the need to more deeply understand the meaning of semiotics and semiotic interpretive work. Several commented that they needed more insight into what is meant by the terms, culture, school culture and everyday culture.

Several of the participants remarked that during the process of engaging in semiotic interpretive inquiry, it was difficult to define and describe ideas surrounding what is meant by everyday culture.

Linnea: I really found the semiotic interpretations of the photos of classrooms and the ways we learned what semiotic messages, or messages... are, but I wonder if I really do know what semiotics is now that I am identifying semiotic readings. I guess I would just like to now look into it more if I am going to teach with such messages.

Although they did well at 'seeing into' and describing their own personal cultural values, at times, several commented that they were not clear about just what the ideas and values that underlie the larger culture are, and wondered if they might be sharing ideas about their cultural values or whether their interpretations might be more matters of personal opinion. Another set of comments made by participants refer to the concern by some that cultural values may be hidden to us and revealed only when we are able to compare what we experience to another culture. Some commented that they felt the need to understand and perhaps study more about the nature of culture and cultural values.

Leam: You know, I am not really sure what my culture is. I grew up in Canada, though my folks are from Scotland. But, I am culturally Canadian, so I should know what my culture is, I think. I don't, I don't think I do. When we talk about the foods of other cultures, it is so clear what they are, like Italian, Chinese. And we talk about the values of some other cultures, but sometimes that just seems so sort of negative or stereotypical. Food culture in Canada? What is that? (Laughs.) French onion soup? Or poutine? There is a national movement to make that the national dish. But it is not from this part, this western part. So, really, I have to think a lot about what IS our culture. How does it, um Canada's culture fit with how I grew up, my parents' influences, that sort of thing.

2. Some participants from other cultures noted that their cultural values may be different from mainstream Canadian cultural values.

Several participants who had not grown up in Canada questioned whether they were able to fully able to represent Canadian cultural values, but commented that they might be in a unique position to provide interesting contrasts by sharing their own backgrounds and experiences with what they observed in their adopted culture.

Jasmine: I wonder if kids really do think about this though, how much they do, or is it just now that we are thinking about this? Where I grew up, in my culture, we were lucky to even have a building, in our small town, a small room as a classroom. I am not sure that I paid much attention to that room, really.

Marja: But this is about looking at your own culture, isn't it? About how the culture sort of determines the messages, and maybe not deliberately, but they show through what we have to work with. And Thomas is saying that it's the culture of another era. You are comparing this to your past experience, in your country and that was the culture of another country.

Shapiro: What do you mean, what are you referring to? Maybe give an example from the elementary school? 
Marc: Well, he, the language teacher, or rather, the ESL teacher was trying to do a lesson at my school with my classroom teacher who knew quite a bit about the Trees and Forests unit... that she has taught many times. That is the kind of thing that I would like to do when I teach, and I think it tells the students that teachers care enough to collaborate together, so they might see that as a message of collaboration, sort of what Thomas was talking about.

One student from Pakistan shared:

Jana: You know, when we did the carbon footprint activity together, I really have to say, that back home, we never talked about things like this. I found the computer program we did very interesting and I did it at home. But is such a new idea to me. Sustainability-and ideas about sustainability lifestyle just is not a part of the culture of education there the way it is here. It is just SO new to me.

3. Some participants noted that social and cultural values surrounding our relationships with the natural environment are changing rapidly and expressed issues and concerns about environmental education in locales where environmental values may be conflicting or politically driven.

Novice teachers noted and discussed the ways that social and cultural values that surround our relationships with the environment are changing rapidly and that the school and other institutional structures may be good places to help learners see major conflicts of interest as we try to examine and locate them. There is some problematizing of the values when, in an oil rich province, for example, there is concern by some members of industry about the messages being overly liberal. Participants mentioned the climate change debate as an example because it has been classified by some as a questionable truth and teachers might find themselves holding one view, while the cultural perspective of big government, parents and others might support another. Some participants remarked that the idea of disrupting culturally constructed messages that are not supportive of the environmental values of a particular community might put them on shaky ground as first year teachers.

Raj: I wonder what a teacher does with the messages of the provincial government about the oilsands when, it is really our major source of revenue here, you know. The government funds education, so, they do have a say... in the curriculum... and they do have a say in the teachers, er, how teachers teach about the industry so to speak. I mean what if a teacher wants to share a different view. Does he get in trouble? Or what is the message to or for students and some of their parents who work in the industry. I wonder if this has been an issue. Like you say, we need to be aware of the controversial issues laws and such. I think I really need to look at that more.

The themes of insight that emerged from the research have led to ongoing conversations with the research study group that I believe enriched novice teachers' insights and, which I hope will influence their future practices. Engagement in the research has informed the ongoing program of research examining the semiotic messages of learning environments. It has also influenced the design of teacher education and professional development experiences for practicing educators.

\section{How the research informs teacher education}

Engagement in the research has informed the ongoing program of research and the design of assignments and learning experiences for preservice educators and practicing teachers in professional and graduate programs. 
The previous, "Organizing and representing the research findings" section describes how the research data was coded and organized into themes to address the research questions. Engagement by research participants went beyond addressing the research questions, and the group appeared to enjoy a strong spirit of co-discovery as they shared and discussed their insights during our group conversations and interviews. This led to many personal conversations outside of our formal time in the schools. Many novice teacher participants described how taking a semiotic perspective allowed them to consider how learning environments speak messages about environmental values in ways they had not encountered previously. Sharing and engaging in a semiotic consideration of messages about the environment in the educational setting helped novice teachers become wide awake to and grasp the idea that the sign giver and the sign receiver do not always share the same code or even the same values and ethics concerning the environment they mutually inhabit. Participants spoke of the way that the discussion led to an expanded view of their role in creating or disrupting these messages.

Another reoccurring aspect of the conversation was references by participants to an interest in learning more about the meaning and influences of their own culture on the teaching/learning dialogue. Many noted new insights into the many ways that larger physical and social structures of learning environments teach about the environment itself as a form of text. They noted how architectural structures in learning environments model environmental values that include the ways that we encourage learners to work with one another to identify and solve environmental issues. As noted in the research findings section, novice practitioners were also led, through involvement in the project to begin to articulate ideas about some of their own professional challenges that they wish to address in their future work in environmental education. Also emerging as a strong theme was a deep recognition that they have a great deal more to learn about the meaning of the concept, culture, and about the nature of semiotic interpretive work and its connection to the design of learning experiences that address environmental topics and issues.

These aspects of the research have informed the ongoing program research project and the design of teacher education and professional development experiences for novice teachers and for experienced practicing educators. Engagement in this project work has provided new insights into the ways that preservice teachers and experienced educators might more effectively explore learning environments for environmental messages by spending more time in classroom settings, in studying curriculum documents, and the ways that teachers interpret and implement curriculum. The research has provided new dialogue sequences and photographs that are shared in class and in inservice and graduate classes as a way of introducing discussions about the ways that learning environments speak environmental messages. These conversations have become an important part of a dialogue designed to help teachers in preparation consider the ways educators reproduce these messages as part of the cultural code.

The research has led to creation of new ways to help build deeper understandings of the meaning of culture for preservice and experienced educators. During the research, participants expressed the need for greater awareness of the meaning and features of their own culture. JoBeth Allen and Linda Labbo (2001) found student teachers in preparation expressing similar concerns in a set of experiences in a literacy education course designed to help student teachers "explore themselves as cultural beings who are teaching in a multicultural society" (p. 40). In their work they found that students had difficulty distinguishing between cultural memoir from autobiography. They usefully built their work around concepts of culture developed by Geneva Gay (2000) in her book, Culturally responsive teaching. She defined culture as "a dynamic system of social values, cognitive 
codes, behavioral standards, worldviews, and beliefs used to give order and meaning to our lives as well as the lives of others... Culture determines how we think, believe, and behave... and how we teach and learn" (pp. 8-9). In the design of coursework experiences for preservice teachers and graduate students, I have created an assignment called "Ecological identity" to help them develop their own definitions of culture. We connect ideas about culture to early life memories, and family history in autobiographical work that examines memories of environmental learning and memories of some of the cultural structures that frame these memories. The energy that participants have shown to continue engaging in this work and their desire to be part of this project has been so clearly expressed, I continue to expand the study by inviting members of the group of novice teachers to speak with my preservice teacher classes about the experiences of using a semiotic lens when considering the messages of classroom learning. These conversations have become an important part of a dialogue designed to help teachers in preparation consider the ways educators reproduce these messages as part of the cultural code. These conversations inform their educational goals. During these conversations, students also begin to identify issues and areas of concern that they want to address in their own future work as teachers.

This activity helps them understand how they may have come to understand their own identities as learners in environmental education, and the messages that they see themselves perpetuating, creating, or disrupting in their future work in the classroom.

The Research Findings section describes how participants have identified topics and approaches to create positive environmental messages and ideas for engaging in further, and I hope that they will pursue these ideas. I will extend the conversation further by following participants into their teaching careers. Ultimately, I hope to follow their work to see what they are doing with what they have learned, and to engage them in a supportive community with one another so that we can continue to explore these ideas together.

Acknowledgments This research was supported by a grant from the Social Sciences and Humanities Research Council of Canada and is acknowledged with gratitude.

Open Access This article is distributed under the terms of the Creative Commons Attribution License which permits any use, distribution, and reproduction in any medium, provided the original author(s) and the source are credited.

\section{References}

Allen, J., \& Labbo, L. (2001). Giving it a second thought: Making culturally engaged teaching culturally engaging. Language Arts, 79(1), 40-52.

Barrett, F. J., \& Fry, R. E. (2005). Appreciative inquiry: A positive approach to building cooperative capacity. Chagrin Falls, OH: Taos Institute.

Bateson, G. (1972). Steps to an ecology of mind. Chicago, IL: University of Chicago Press.

Bauer, J. (2006). Forging environmentalism: Justice. livelihood and contested environments. Armonk, NY: M. E. Sharpe.

Corbett, J. B. (2006). Communicating nature: How we create and understand environmental messages. Washington, DC: Island Press.

de Saussere, F. (1959). Course in general linguistics. (C. Bally \& A. Sechehaye, Trans.). London: Peter Owen Philosophical Library.

Fien, J. (1993). Ideology critique and environmental education. In J. Fien (Ed.), Education for the environment (pp. 14-19). Geelong, Victoria, Australia: Deakin University Press.

Fogelberg, K. (in press). Unsilencing voices: A study of zoo signs and their language of authority. Cultural studies in science education. 
Gay, G. (2000). Culturally responsive teaching. New York: Teachers College Press.

Peirce, C. S. (1985). Logic as semiotics: The theory of signs. In R. E. Innis (Ed.), Semiotics: An introductory anthology (pp. 4-27). Bloomington, IN: Indiana University Press.

Sebeok, T. (2001). Signs: An introduction to semiotics. Toronto, Canada: University of Toronto Press.

Shapiro, B. (2010). Research resources to study the environmental messages of school learning settings. In

D. Berlin \& A. L. White (Eds.), Promising practices to meet global challenges in science and mathematics education (pp. 51-59). Columbus, OH: International Consortium for Research in Science and Mathematics Association. The Ohio State University.

Shapiro, B. (2012). Structures that teach: Using a semiotic interpretive framework to study the environmental messages of learning settings. Journal of eco-thinking, 1, 1-15.

Shapiro, B., Kirby, D. (1998). An approach to consider the semiotic messages of school science learning culture. Journal of Science Teacher Education, 9, 221-240, doi.org/10.1023/A:1009402023896.

Shapiro, B., Richards, L., Ross, N., Kendal-Knitter, K. (1999). Time and the environments of schooling. Learning environments research, 2, 1-19, doi.org/10.1023/A:1009991421940.

Thomashow, M. (2002). Ecological identity: Becoming a reflective environmentalist. Cambridge, MA: MIT Press.

Bonnie Shapiro is a Professor in the Werklund School of Education at the University of Calgary, Canada, conducting research and teaching in Graduate and Undergraduate Programs. She specializes in Science and Environmental Education and interpretive research approaches. Bonnie Shapiro designed and is Academic Coordinator for the newly launched Interdisciplinary M.Ed. Program, Education for the environment. 